\title{
PERANCANGAN SISTEM COMPUTER BASED TESTING BERBASIS WEB PADA SEKOLAH DASAR
}

\author{
David Refandy ${ }^{1}$, Emmy Wahyuningtyas ${ }^{2}$ \\ 1,2Program Studi Informatika, Fakultas Teknik, Universitas Wijaya Kusuma Surabaya \\ davidrefandy@gmail.com, Emmy@if.uwks.ac.id
}

\begin{abstract}
Abstrak
SDN PETEMON IX adalah jenjang pendidikan sekolah dasar yang berlokasi di Jl. Pacuan Kuda No. 43 SURABAYA. Sistem penilaian pada SDN PETEMON IX masih menggunakan cara yang manual dan menghabiskan banyak waktu dalam mengolah nilai. Oleh karena itu dibutuhkannya sistem Computer Based Testing yang bertujuan untuk dapat membantu dalam proses mengolah nilai dan juga mengurangi penggunaan kertas secara berlebihan. Metode yang digunakan dalam merancang sistem ini adalah metode waterfall, dengan adanya sistem ini dapat membantu dalam menyelesaikan permasalahan yang ada pada SDN PETEMON IX. Hasil dari sistem ini yaitu dapat membantu guru dalam melakukan penilaian terhadap ujian siswa, sistem dapat membantu kegiatan pada SDN PETEMON IX, dan sistem dapat memberikan pembobotan pada setiap butir soal yang akan diinputkan. Kesimpulan dari penelitian ini yaitu Sistem Computer Based Testing dapat memberikan hasil nilai ujian siswa secara langsung tanpa mengoreksinya secara manual.
\end{abstract}

Kata Kunci : Online Test, Computer Based Test, CBT.

\begin{abstract}
SDN PETEMON IX is an elementary school education located on Jl. Pacuan Kuda No. 43 SURABAYA. The delivery system at SDN PETEMON IX still uses manual methods and spends a lot of time processing values. Therefore a Computer Based Testing system is needed which aims to be able to assist in the value processing process and reduce the use of excessive paper. The method used in designing this system is the waterfall method, with this system it can help solve problems that exist in SDN PETEMON IX. The results of this system are that it can assist teachers in conducting student examinations, the system can assist activities at SDN PETEMON IX, and the system can provide weighting for each item to be inputted. The conclusion of this study is that the Computer Based Testing System can provide the results of student scores directly without correcting them manually.
\end{abstract}

Keywords: Online Test, Computer Based Test, CBT.

\section{PENDAHULUAN}

Pembelajaran Nasional yang bersumber pada Pancasila serta Undang- Undang Dasar Negeri Republik Indonesia Tahun 1945 yang bisa meningkatkan keahlian serta membentuk sifat dan peradaban bangsa yang bermartabat dalam rangka mencerdaskan kehidupan bangsa, bertujuan untuk meningkatkan kemampuan partisipan didik agar menjadi manusia beriman dan bertakwa kepada Tuhan Yang Maha Esa, berakhlak mulia, sehat, berilmu, cakap, kreatif, mandiri, serta jadi masyarakat negeri yang demokratis dan bertanggung jawab. Buat meningkatkan guna tersebut pemerintah menyelenggarakan sesuatu Sistem Pembelajaran Nasional sebagaimana tercantum dalam UndangUndang No 20 Tahun 2003 tentang Sistem Pembelajaran Nasional.

Pada Sekolah Dasar Negeri Petemon IX terdapat satu permasalahan yaitu dalam mengolah nilai siswa. Guru memberikan nilai masih dengan cara manual dengan mengoreksi hasil ujian siswa yang masih menggunakan kertas dalam ujian, sehingga menghabiskan banyak waktu. Agar lebih efektif dalam mengolah nilai hasil ujian siswa, sebaiknya media pendidikan selaku perlengkapan bantu buat evaluasi semacam Computer Based Testing (CBT), “ Dengan kemajuan teknologi, aplikasi evaluasi bisa jadi nanti hendak berbeda dengan wujud evaluasi saat ini yang mayoritas masih memakai pena serta kertas"[1].

Penelitian ini peneliti mempunyai gagasan untuk membuat sistem yang dapat membantu guru dalam melakukan penilaian kepada siswa menggunakan Computer based Testing (CBT) pada Sekolah Dasar Negeri Petemon IX. Untuk mengatasi permasalahan yang terjadi dalam hal penilaian hasil ujian siswa diperlukan sebuah sistem yang berjudul "Perancangan sistem Computer Based Testing Berbasis Web Pada 
Pendidikan Sekolah Dasar”. Pada sistem ini guru dan siswa dapat langsung melihat hasil ujian yang telah dikerjakan.

\section{TINJAUAN PUSTAKA}

\subsection{CBT (Computer Based Test)}

Computer Based Test (CBT) ialah tes yang dikerjakan memakai pc, jadi tidak membutuhkan kertas, pena ataupun pensil buat menanggapi pertanyaan. Seluruh soal serta lembar jawaban pula disediakan di pc sehingga kita cuma tinggal menekan jawaban benar ataupun salah ataupun mengetik saat menanggapi persoalan esay.

CBT ini banyak memakai di bermacam bidang semacam bidang pembelajaran ataupun di dunia kerja. Di bidang pembelajaran umumnya dipakai buat memastikan berapa nilai paling tinggi seseorang siswa ataupun mahasiswa dalam memahami satu mata pelajaran ataupun mata kuliah. Sebaliknya di dunia kerja, CBT digunakan buat mengenali keahlian dasar dari seseorang pelamar pekerjaan sehingga memudahkan bagian HRD dalam menyeleksi calon karyawan.

1. Computer Based Testing (CBT) merupakan tes ataupun penilaian pendidikan yang dicoba memakai komputer[2].

2. Pemakaian Computer Based Testing juga lumayan gempar digunakan dalam dunia industri. Spesialnya merupakan saat penerimaan pekerja, di mana para pelamar di tes serta hasil tes tersebut bisa langsung dilihat[3].

Jadi, secara totalitas bisa dikenal kalau aplikasi CBT merupakan selaku perlengkapan ataupun perantara yang diciptakan dengan tujuan supaya pengguna bisa lebih gampang dalam mengerjakan suatu ataupun tercapainya tujuan tertentu.

CBT ialah uji ataupun penilaian yang dikerjakan dengan memakai pc. Ciri dari uji ini sama dengan uji konvensional ialah memakai satu fitur uji buat sebagian partisipan dengan uji yang serupa. Memiliki perbedaan dalam penyampaiannya, setiap soal yang tidak memakai kertas, untuk membuat soal - soal ujian ataupun jawaban dari soal tersebut. Sistem nilai ataupun pencocokan jawaban langsung dicoba lewat pc. Umumnya partisipan bias mengerjakan serta memandang butir soal dari no awal hingga dengan terakhir.

Terdapat 4 wujud uji berbasis pc yang dibesarkan, ialah:

1. Model Terbuka Uji dengan model ini, merupakan dimana partisipan uji bisa diiringi oleh siapapun tanpa wajib lewat pendaftaran terlebih dulu serta pula tanpa pengawasan siapapun. Contohnya uji yang bisa diakses langsung lewat internet umumnya berbentuk permainan / game).

2. Model Terkendali Nyaris sama dengan Model Terbuka, tetapi partisipan uji cuma diperuntukkan untuk yang telah terdaftar dengan metode memasukkan username serta Password.

3. Model Supervisi yaitu, model ini ada Supervisor yang mengenali partisipan uji buat diotentikasi serta memvalidasi keadaan pengambilan uji.

4. Model Pengaturan yaitu, uji yang umumnya dicoba pada satu tempat. Suatu kelompok yang mengendalikan proses uji bisa mendefinisikan serta mengoptimalkan kinerja serta ciri perlengkapan di satu tempat uji. Dibutuhkan operator ahli buat mengendalikan alur uji / penilaian saat sedang terlaksana[4].

\subsection{Pengertian Pendidikan}

Definisi pendidikan ialah upaya untuk memanusiakan manusia muda[5]. pengertian lain dari pendidikan ialah gabungan dari suatu perkembangan atau pertumbuhan insan dengan warusan sosial. Pendidikan juga merupakan suatu penciptaan dalam hati nurani, pendidikan juga menjadi proses penciptaan diri serta tolak ukur diri secara etis yang sesuai dengan serasi dengan hati nurani[6].

Guna dari pembelajaran ialah sangat besar, perawatan dan reparasi kehidupan warga. dimana warga terbawa rasa tanggung jawab ke dalam warga. Jadi pembelajaran ialah sesuatu aktivitas sosial yang wajib senantiasa dibesarkan serta senantiasa terdapat didalam area warga yang lingkungan. Peranan pembelajaran yakni mengalami spesialisasi dan melembaga dengan pembelajaran resmi yang terletak di lingkup sekolah ataupun dengan pembelajaran informal yang terletak diluar lingkup sekolah[6].

\subsection{Flowchart}

Flowchart adalah suatu gambaran atau grafik yang menggambarkan urutan atau langkah - langkah dari suatu sistem atau program. Flowchart juga dapat membantu dan menolong programmer atau analis untuk memecahkan masalah jika terdapat suatu kendala sehingga memudahkan programmer atau analis pada saat membuat sistem maupun program[7].

\subsection{XАMPP}

XAMPP adalah suatu aplikasi untuk pemrograman web yang lengkap dan dapat digunakan untuk belajar pemrogramaan web, khususnya menggunakan bahasa pemrograman dari PHP dan MySql[9].

XAMPP merupakan aplikasi atau software yang berbasis open source dan XAMPP ini juga dikembangkan oleh komunitas Open Source. Aplikasi ini juga memudahkan programmer karena beberapa paket sudah disediakan oleh XAMPP, seperti : Apache, MySql, Php, FileZilla, dan Phpmyadmin[8]. 
XAMPP adalah aplikasi atau software yang dapat di unduh dengan mudah dan gratis. Aplikasi ini juga dapat diakses disemua sistem operasi seperti linux, mac, solaris, dan windows[10].

\subsection{DFD (Data Flow Diagram)}

Data Flow Diagram adalah suatu diagram yang menggambarkan tentang alur data, seperti sistem ke entitas atau sebaliknya yaitu entitas ke dalam sistem. DFD dapat diartikan juga sebagai teknik yang bisa menjabarkan alur data dari masuknya data menuju hasil dari data atau output[11].

\section{HASIL DAN PEMBAHASAN}

\subsection{Tahap Penelitian}

Berikut ini merupakan alur dari metode penelitian proses Perancangan Sistem Computer Based Testing pada SDN PETEMON IX.

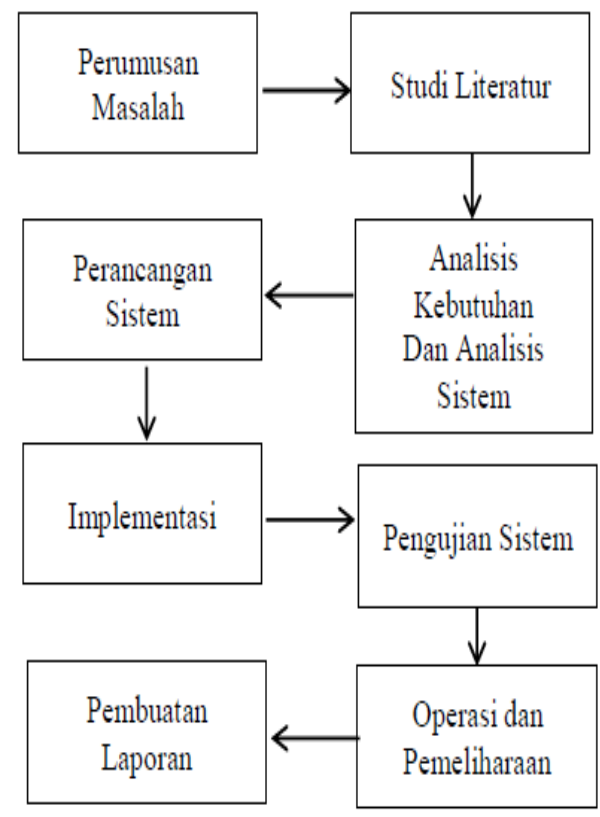

Gambar 3.1 Diagram Alur Penelitian.

\subsubsection{Perumusan Masalah}

Pada tahap perumusan masalah ini, penulis melakukan observasi ke SDN PETEMON IX. Dari observasi tersebut, mendapatkan kendala atau masalah pada sistem yang dapat menghambat guru dalam melakukan pengolahan nilai. Oleh sebab itu penulis menentukan beberapa rumusan masalah sesuai hasil dari observasi untuk dijadikan acuan dan tujuan penelitian.

\subsubsection{Studi Literatur}

Tahap studi literatur adalah mencari referensi teori yang relevan dengan permasalahan yang telah ditemukan. Referensi ini bisa dicari dari buku atau jurnal. Hasil dari studi literatur ini adalah terkumpulnya referensi yang relevan dengan perumusan masalah, sehingga tujuannya adalah memperkuat perumusan masalah serta sebagai landasan teori dalam melakukan "Perancangan Sistem Computer Based Testing Berbasis Web" pada SDN PETEMON IX.

\subsubsection{Analisis Sistem}

Tahap analisa sistem ini dilakukan untuk menganalisa kebutuhan sistem yang diperlukan yaitu alur data dan data yang diperlukan oleh oleh pengguna.

\subsubsection{DFD Level Context}

Pada diagram level context ini dijelaskan tentang proses secara umum yang terjadi pada sistem computer based testing, dimana alur data dan informasi saling terkait satu sama lain.

\subsection{Flowchart Proses Bisnis}

Pada tahap ini terdapat proses bisnis, yaitu sistem computer based testing yang dijabarkan dan dijelaskan sebagai berikut :

\subsubsection{Flowchart Proses Bisnis Input Soal dan Jawaban}

Pada Flowchart proses bisnis input soal dan jawaban. Guru harus login terlebih dahulu. Setelah login guru akan menginput soal dan jawaban yang ingin dimasukan kedalam sistem untuk di ujiankan.

\subsubsection{Flowchart Proses Bisnis Pengerjaan Ujian}

Pada Flowchart proses bisnis pengerjaan ujian ini, Siswa login terlebih dahulu jika siswa salah memasukan username atau password maka siswa harus login lagi dengan memasukan username dan password dengan benar. Setelah login Siswa langsung mengerjakan ujian yang sudah dijadwalkan, setelah mengerjakan ujian siswa dapat langsung melihat hasil ujian.

\subsection{Data Flow Diagram Level 1}

Setelah membuat gambaran rancangan DFD level context maka dijabarkan menjadi DFD level 1 yang terdapat beberapa proses yaitu Jadwal, kelola data master, pembuatan room ujian, Daftar Siswa, input soal dan jawaban, mengerjakan ujian, perhitungan nilai, laporan nilai.

\subsection{Conceptual Data Mode (CDM)}

Merupakan gambaran struktur basis data yang entitas dan relasi saling berhubungan. Conceptual Data Model pada sistem Computer Based Testing ini memiliki 8 entitas dan 9 relasi. Entitas tersebut terdiri dari m_user, m_guru, tr_guru_mapel, m_siswa, m_soal, m_mapel, tr_ikut_ujian, tr_guru_tes, dan pada entitas tersebut memiliki atribut masing masing. 


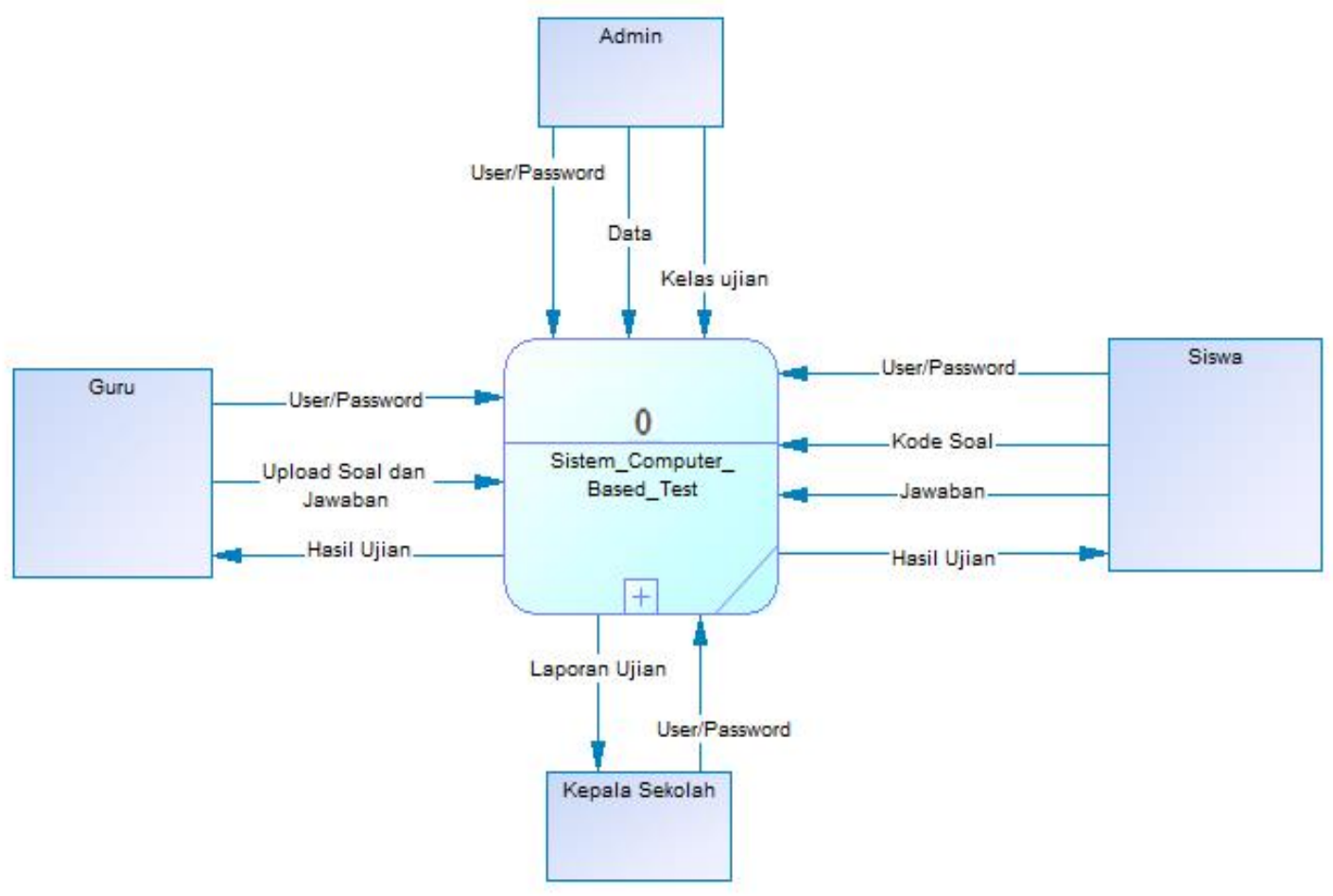

Gambar 3.2 DFD Level Context.

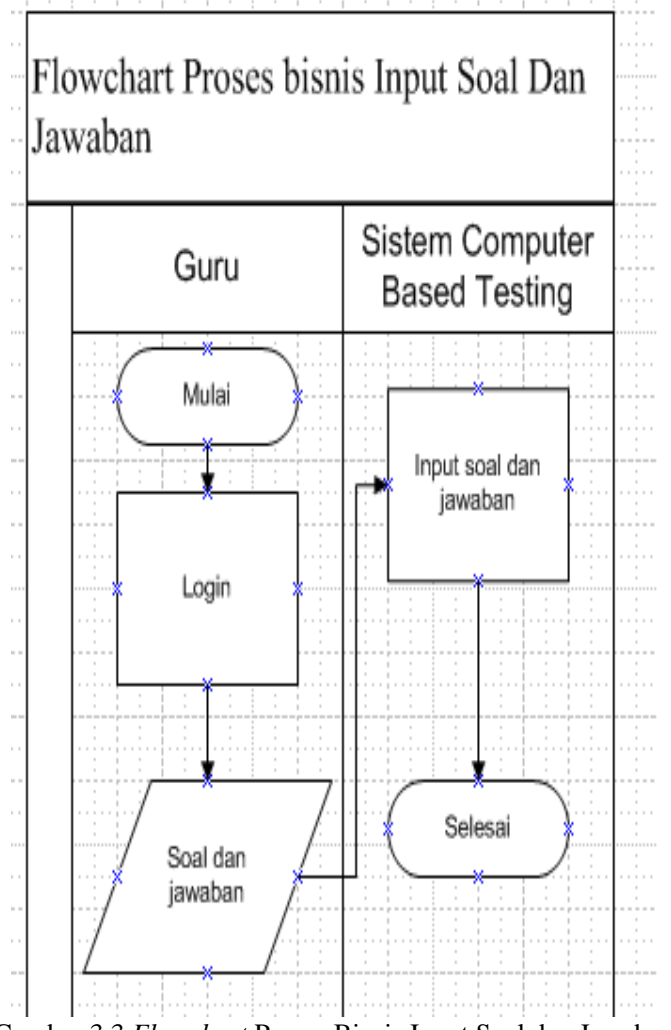

Gambar 3.3 Flowchart Proses Bisnis Input Soal dan Jawaban

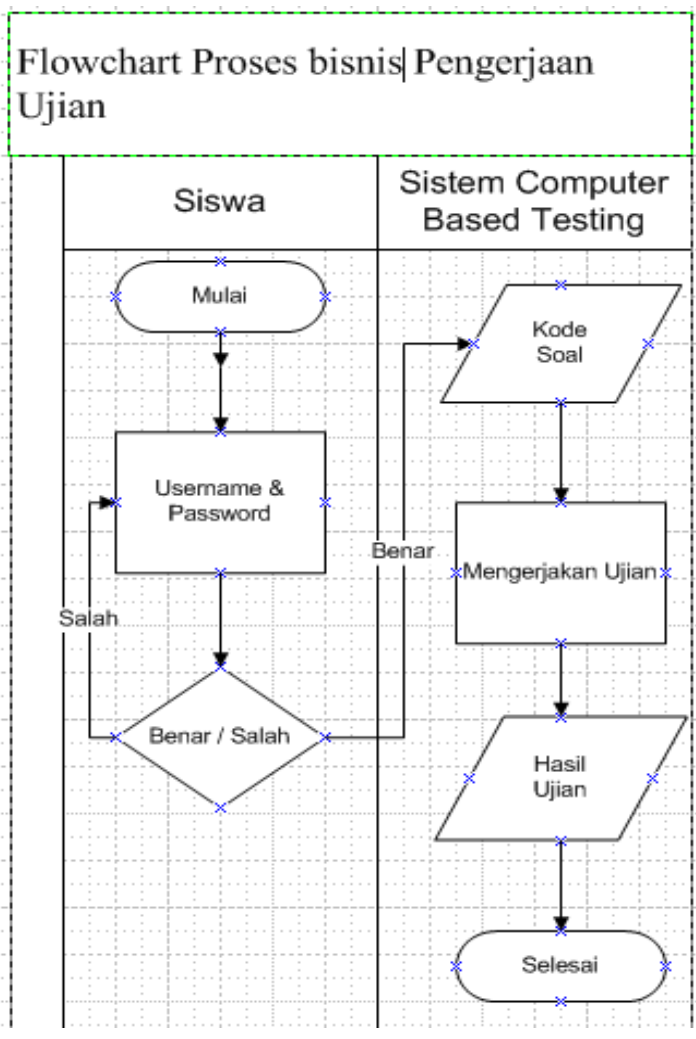

Gambar 3.4 Flowchart Proses Bisnis Pengerjaan Ujian. 


\section{pISSN: 2442-3386 elSSN: 2442-4293}

Melek IT Vol 1 No 1 Jan - Jun 2021, 71 - 76 INFORMAIIONIECHNOLOGY JOURNAL
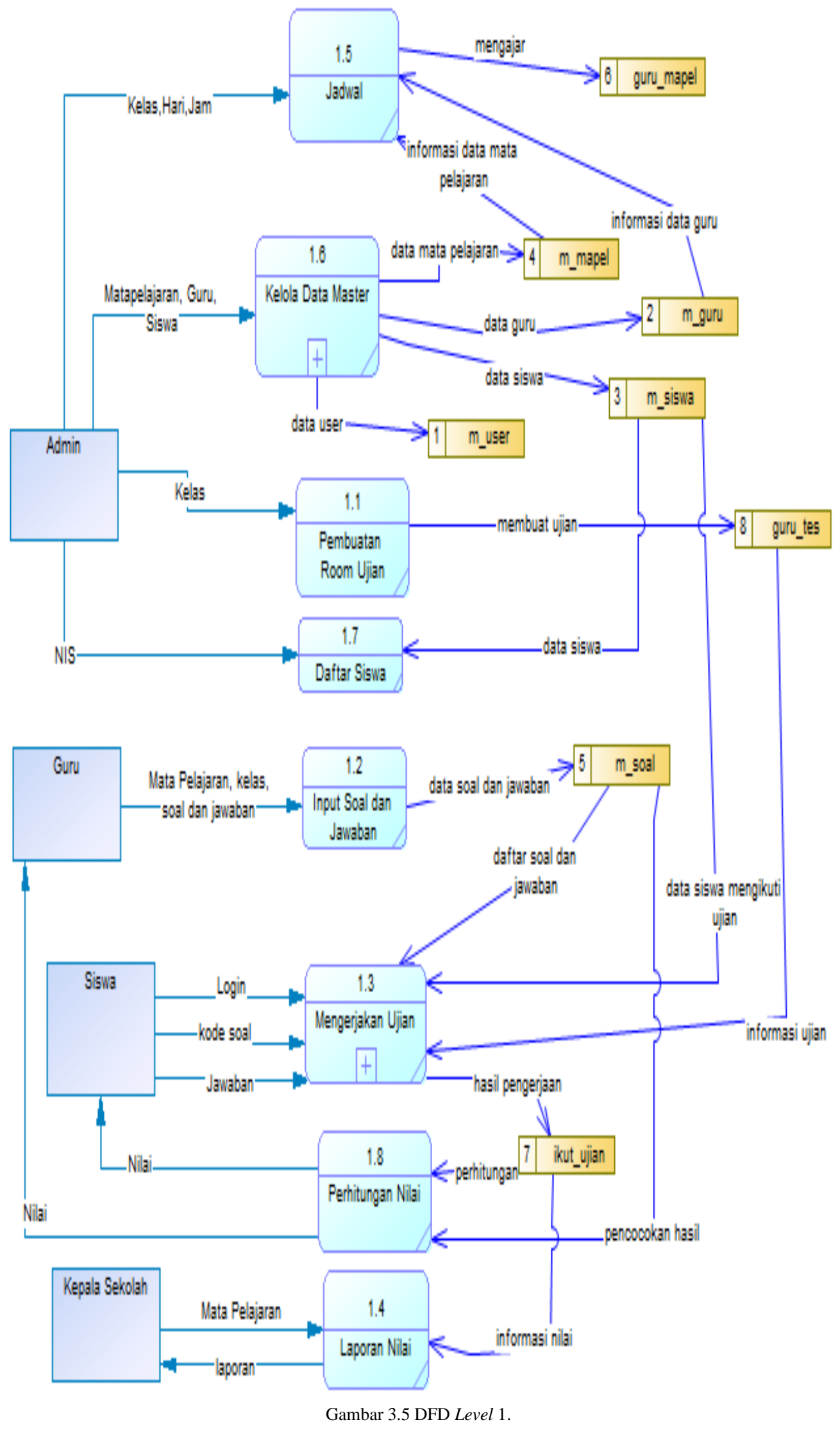


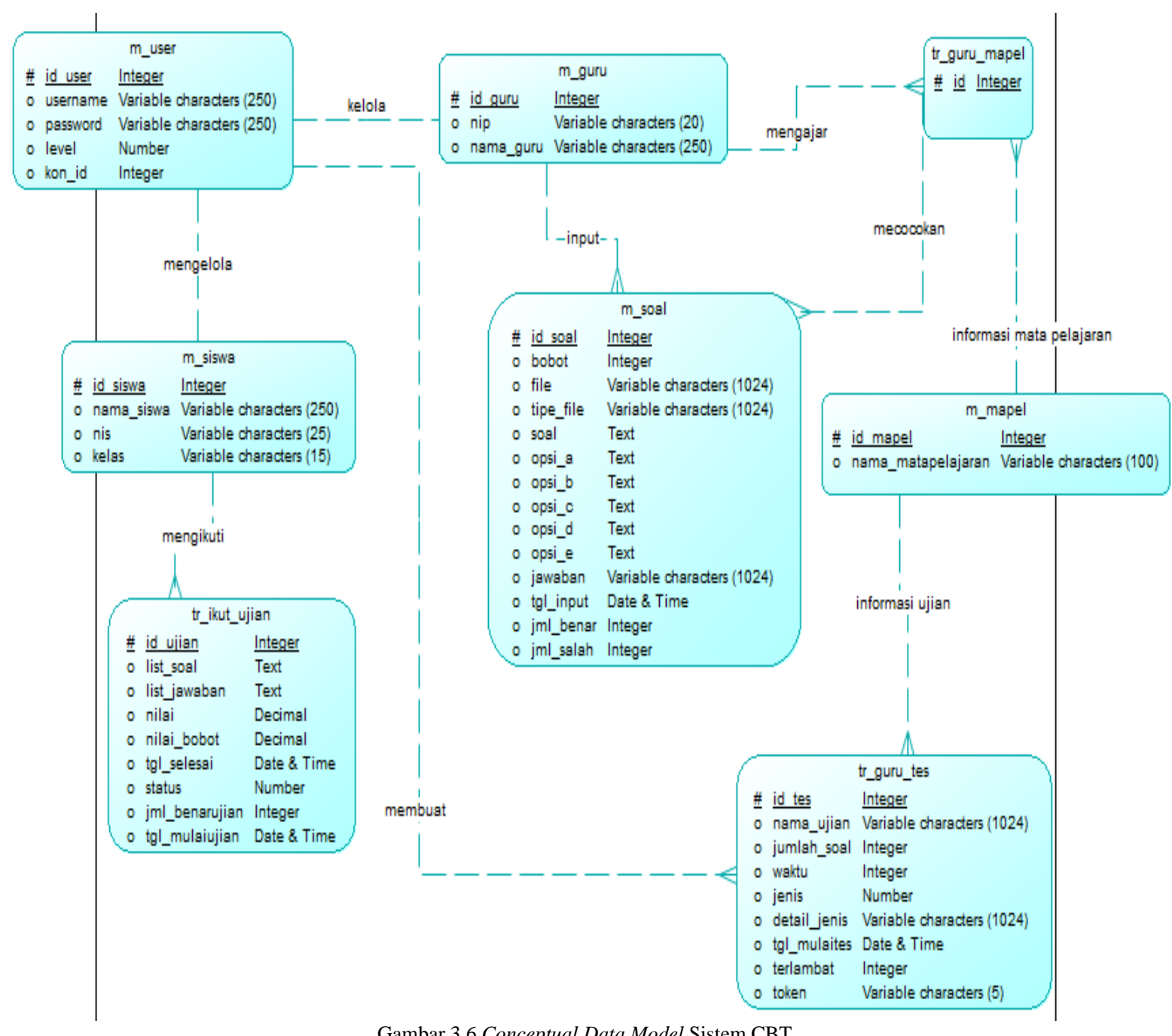

Gambar 3.6 Conceptual Data Model Sistem CBT.

\subsection{Implementasi}

Pada implementasi ini membahas berdasarkan perancangan sistem. Implemestasi perancangan ini meliputi tentang :

\subsection{Halaman Login}

Pada tampilan ini, semua user yang akan mengakses sistem ini harus memasukan username dan password agar dapat masuk ke dalam sistem.

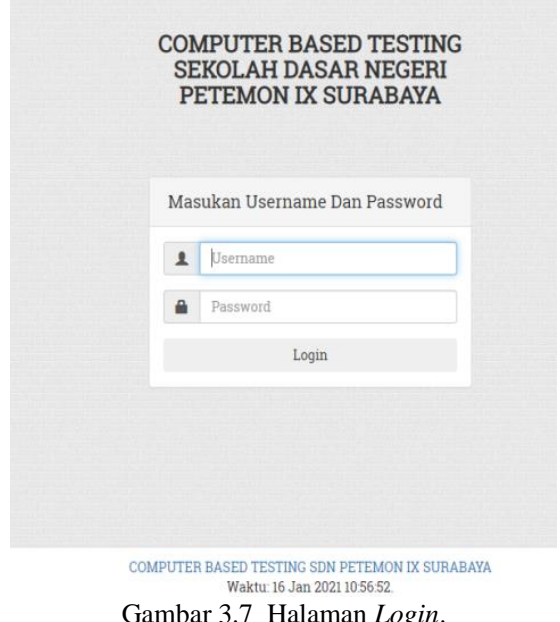

\subsection{Halaman Dashboard Admin}

Pada halaman dashboard admin ini menampilkan tampilan data siswa, data guru, data mata pelajaran, data soal, hasil jawaban, tampilan selamat datang.

Computer Based Testing SDN PETEMON SURABAYA

Adminstatar Pusat (datmin)

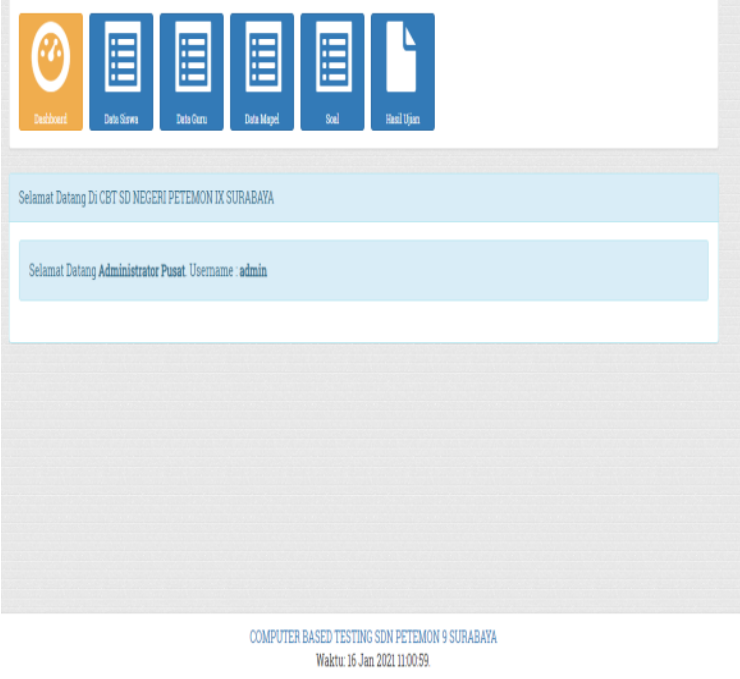

Gambar 3.8 Halaman Dashboard admin. 


\section{pISSN: 2442-3386 elSSN: 2442-4293}

\subsection{Halaman Data Siswa}

Pada halaman ini menampilkan data siswa yang terdiri dari nama, NIS, kelas dan terdapat tampilan tambah untuk menambah data siswa.

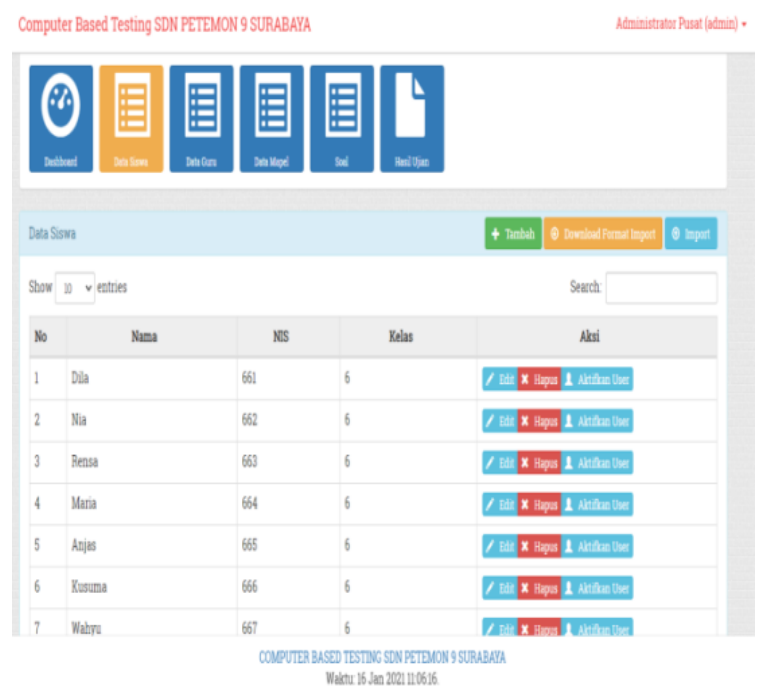

Gambar 3.9 Halaman Data Siswa.

\subsection{Halaman Data Guru}

Pada halaman tampilan ini menampilkan data guru yang berisikan data nama guru, nip dan terdapat tampilan tambah untuk menambahakan data guru. Ada juga import untuk import data guru.

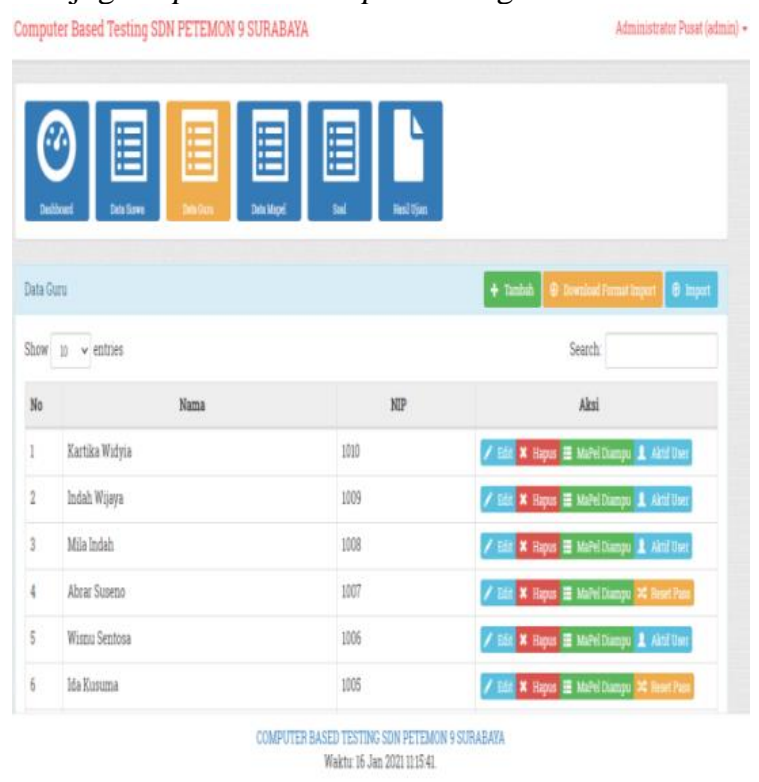

Gambar 3.10 Halaman Data Guru.

\subsection{Halaman Dashboard Guru}

Pada halaman dashbboard ini menampilkan tampilan soal untuk input soal dan jawaban, ujian yang akan mau diujiankan, hasil ujian.
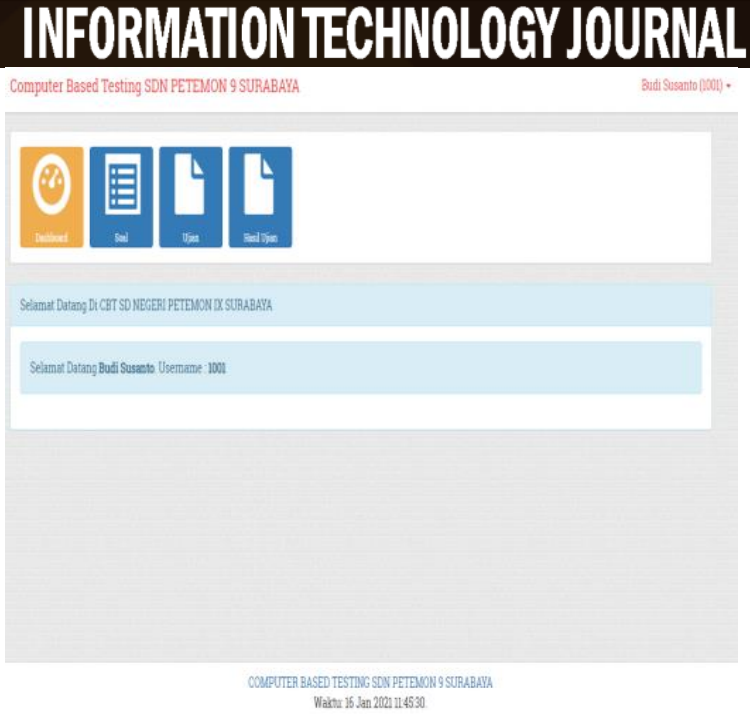

Gambar 3.11 Halaman Dashboard Guru.

\subsection{Halaman Membuat Ujian}

Pada tampilan halaman ini menampilkan untuk membuat room ujian yang terdiri dari nama ujian, mata pelajaran yang akan diujiankan, jumlah soal, tanggal mulai, keterlambatan, dan pengacakan soal.

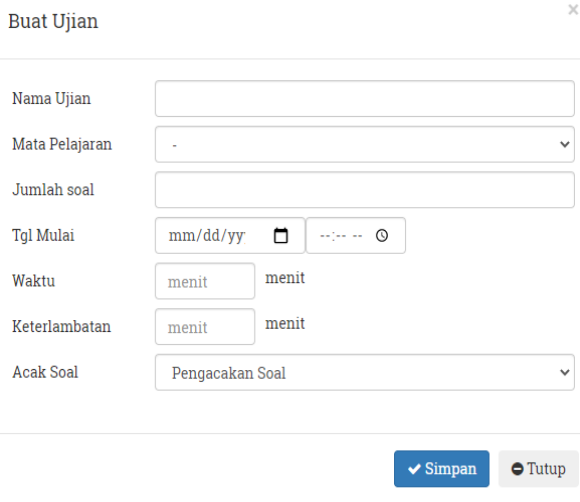

Gambar 3.12 Tampilan Halaman Membuat Ujian.

\subsection{Halaman Dashboard Siswa}

Tampilan ini menunjukan dashboard siswa hanya menampilkan tampilan dashboard, tampilan ujian dan tampilan selamat datang.

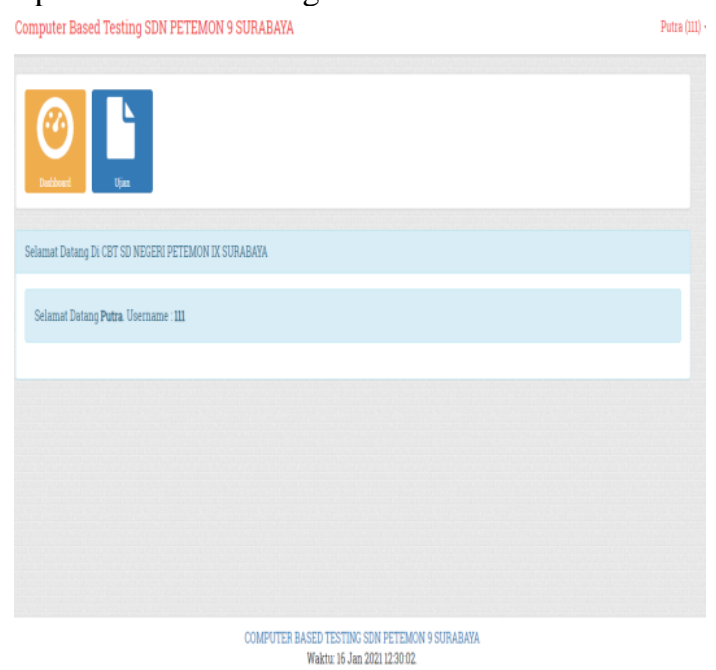

Gambar 3.13 Halaman Dashboard Siswa 


\subsection{Halaman Informasi Ujian Siswa}

Pada halaman ini menampilkan informasi Ujian siswa yang akan melakukan ujian yang berisikan data nama siswa, nis, nama guru, nama ujian, jumlah soal, waktu ujian, token.

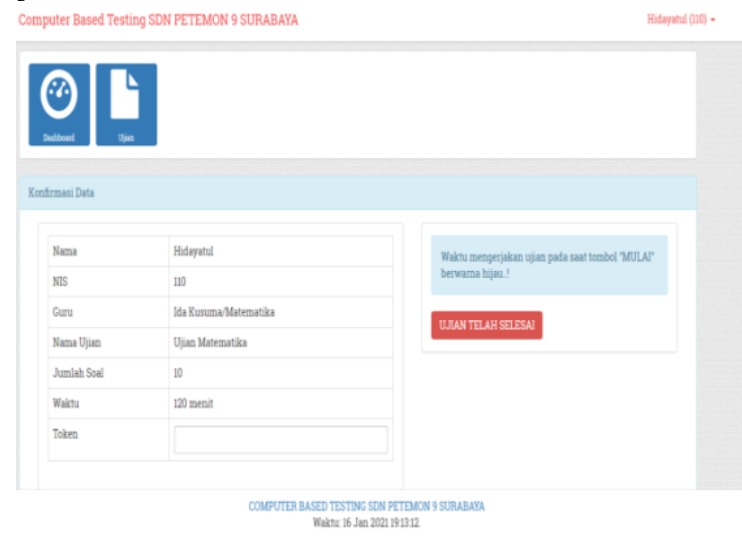

Gambar 3.14 Halaman Informasi Data Ujian Siswa.

\subsection{Halaman Ujian Siswa}

Pada tampilan halaman ini menunjukan bagaimana proses tampilan siswa mengerjakan ujian terdapat navigasi soal, waktu ujian, dan selesai ujian untuk mengakhiri ujian.

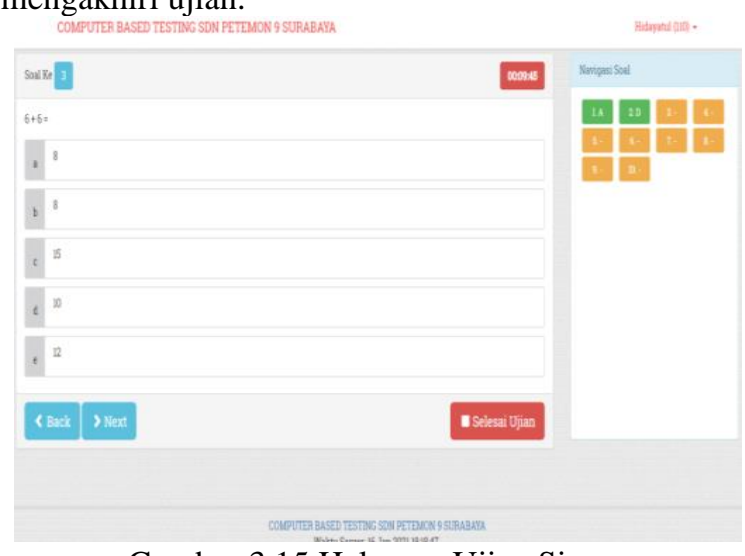

Gambar 3.15 Halaman Ujian Siswa.

\subsection{Halaman Informasi Selesai Ujian}

Tampilan halaman ini menunjukan siswa telah menyelesaikan ujian yang telah ada dan siswa pun langsung mendapat hasil ujian yang telah selesai di kerjakan.

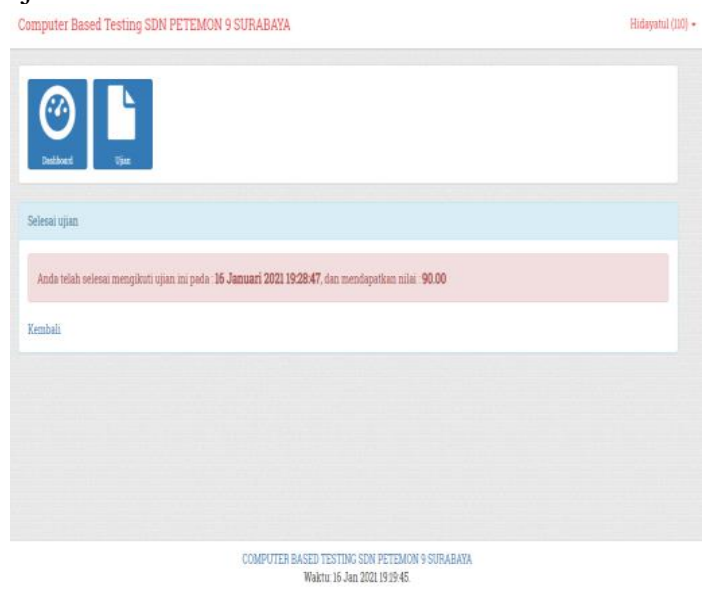

Gambar 3.16 Halaman Informasi Selesai Ujian.

\subsection{Halaman Hasil Ujian}

Halaman ini menampilkan hasil ujian siswa yang telah mengerjakan ujian siswa dengan mata pelajaran sudah disiapkan oleh guru.

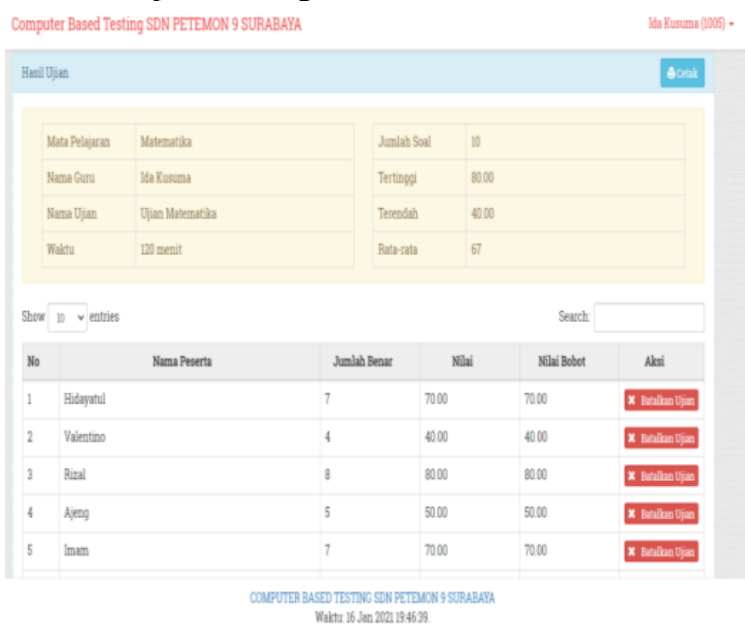

Gambar 3.17 Halaman Hasil Ujian.

\subsection{Halaman Cetak Laporan Hasil Ujian}

Tampilan ini menghasilkan cetakan laporan hasil ujian siswa dengan dijabarkannya detail ujian yang berisikan nama matapelajaran, nama guru, nama ujian, jumlah soal, waktu, nilai tertinngi, nilai terendah, dan nilai rata - rata. Tabel yang bawah merupakan hasil dari siswa.

\begin{tabular}{|c|c|}
\hline Detail Vjan & \\
\hline Ietap Pelagan & Mternotha \\
\hline Vlama Gru & batusuma \\
\hline Vanal Jian & Ujan Natannalia \\
\hline Jurlath Syal & 10 \\
\hline N13tus & 1w wenth \\
\hline 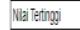 & 8000 \\
\hline Pial Teredoth & 4000 \\
\hline Nial Rajaratata & 67 \\
\hline
\end{tabular}

\begin{tabular}{|c|c|c|c|c|}
\hline \multicolumn{5}{|c|}{ Asil Vjan } \\
\hline 110 & Vamp Peserata & Jumbin Benar & Nilia & Nisis Bocot \\
\hline 1 & Prota & 8 & 8000 & 8000 \\
\hline 2 & Heriv & 8 & 8000 & 8000 \\
\hline 3 & han & 7 & 7000 & 7000 \\
\hline 4 & Bazs & 7 & 7000 & 1000 \\
\hline 5 & han & 6 & 6000 & 6000 \\
\hline 6 & Iman & 7 & 7000 & 7000 \\
\hline 7 & Akng & 5 & 5000 & 5000 \\
\hline 8 & Rizal & 8 & 8000 & 8000 \\
\hline 9 & veanino & 4 & 4000 & 4000 \\
\hline 10 & Hodadala & 7 & 7000 & 7000 \\
\hline
\end{tabular}

Gambar 3.18 Halaman Cetak Laporan Hasil Ujian.

\section{PENUTUP}

\subsection{Kesimpulan}

Berdasarkan dari hasil dan analisan terhadap Sistem Computer Based Testing pada pendidikan sekolah dasar telah dibuat, kesimpulannya sebagai berikut :

1. Sistem Computer Based Testing dapat membantu guru dalam memberikan penilaian terhadap siswa. 
2. Sistem dapat menampilkan hasil ujian yang dikerjakan oleh siswa.

\subsection{Saran}

Saran dari hasil dan analisis terhadap Sistem Computer Based Testing yang telah dibuat yaitu pengembangan Sistem Computer Based Testing Berbasis WEB Pada Pendidikan Sekolah Dasar agar ditambahkannya beberapa fitur agar sistem lebih baik, seperti siswa dapat mendownload materi ujian agar siswa dapat mempelajarinya kembali.

\section{DAFTAR PUSTAKA}

[1] Santrock, (2008). Psikologi Pendidikan, Edisi Kedua. Jakarta : kencana.

[2] Sutopo, H. Pengembangan Evaluasi Pembelajaran Berbasis Multimedia dengan Flash, PHP, dan MySQL. Jurnal Informatika, Vol. 10, No. 2, November 2009, ISSN: $1693-$ 3877, eISSN: 2407-1544.

[3] S. Al-Amri, 2011 "Computer-Based Testing vs. Paper-Based Testing: A Comprehensive Approach to Examining the Comparability of Testing Modes". Essex Graduate Student Papers in Language \&Linguistics, Vol. 10, 2008, hal. 22-44.

[4] Bartram, Dave SHL Group plc, Thames Ditton, Surrey, UK dan Hambleton, Ronald K, University of Massachusetts at Amherst, USA, Computer-Based Testing and the Internet, 2001.

[5] Driyarkara. Driyarkara Tentang Pendidikan , Yayasan Kanisius, Yogyakarta, 1950, hlm.74.

[6] Hasbullah. Dasar Ilmu Pendidikan. 2005. Jakarta. Penerbit: PT RajaGrasindo Persada.

[7] Jogiyanto HM, Akt, MBA, Ph. D, Analisis \& Desain Sistem Informasi, (edisi kedua, cetakan kedua), Andi Offset, Yogyakarta,2002.

[8] Bunafit Nugroho, 2011, Membuat Sistem Informasi Penjualan Berbasis Web dengan PHP dan MySQL, Penerbit GAVA MEDIA, Yogyakarta.

[9] Nugroho, Bunafit. 2013. Dasar Pemograman Web PHP \pm MySQL dengan Dreamweaver. Yogyakarta: Gava Media.

[10] Buana, I Komang Setia. 2014. "Jago Pemograman PHP”. Jakarta:Dunia Komputer.

[11] Santoso, Wan Yuliyanti. 2016. "Perencanaan dan pembuatan aplikasi absensi dosen menggunakan radio frequency identification (RFID) (studi kasus politeknik tanah laut)", SENIATI, ITN Malang, pp E53-1 E53-7. 
Melek IT

Information Technology Journal. Vol 7 No 1 Januari 2021, 76 - 76 